Revta brasil. Bot., São Paulo,V.24, n.4 (suplemento), p.527-536, dez. 2001

\title{
Estudo polínico em plantas de restinga do Estado do Rio de Janeiro - Clusiaceae Lindl.
}

\author{
VANIA GONÇALVES-ESTEVES ${ }^{1,2}$ e CLAUDIA BARBIERIFERREIRA MENDONÇA ${ }^{1}$
}

(recebido: 4 de setembro de 2000; aceito: 30 de maio de 2001)

\begin{abstract}
Polinic study in plants from "restinga" in the state of Rio de Janeiro - Clusiaceae Lindl.). This work deals with the palylonogy of eight species of Clusiaceae: Calophyllum brasiliense Cambess., Clusia criuva Cambess., C. hilariana Schltdl., C. lanceolata Cambess., C. parviflora (Sald.) Engl., Garcinia brasiliensis Mart., Kielmeyera membranacea Casar. e Symphonia globulifera L.f. The pollen material was acetolysed, measured, described and illustrated with photo or eletronmicrography (SEM). The main features of the pollen grains were studied: shape, size, exine constitution and aperture type. The pollen grains of Clusiaceae were small, medium or large in size, suboblate, oblate-spheroidal, prolate-spheroidal or subprolate, isopolar, porate (3-6) or 3-colporate, very small, small or large polar area, with rugulate or reticulate exine. It is concluded that the genera and the species can be separated by palynological characters, constituting an euripalynous group.

RESUMO - (Estudo polínico em plantas de restinga do Estado do Rio de Janeiro - Clusiaceae Lindl.). Este trabalho trata da palinologia de oito espécies de Clusiaceae: Calophyllum brasiliense Cambess., Clusia criuva Cambess., C. hilariana Schltdl., C. lanceolata Cambess., C. parviflora (Sald.) Engl., Garcinia brasiliensis Mart., Kielmeyera membranacea Casar. e Symphonia globulifera L.f. Os grãos de pólen foram acetolisados, medidos, descritos e ilustrados sob microscopia de luz e microscopia eletrônica de varredura (MEV). Foram estudadas as principais características dos grãos de pólen como forma, tamanho, constituição da exina e aberturas. Constatou-se que os grãos de pólen foram pequenos, médios ou grandes, suboblatos, oblatoesferoidais, prolato-esferoidais ou subprolatos, isopolares, porados (3-6) ou 3-colporados, área polar muito pequena, pequena ou grande, exina rugulada ou reticulada. Os autores concluem que os gêneros e as espécies podem ser separados, palinologicamente, tratando-se portanto, de um grupo euripolínico.
\end{abstract}

Key words - Palynology, Clusiaceae, restinga, pollen

\section{Introdução}

Clusiaceae é uma família com poucos representantes nas restingas do Estado do Rio de Janeiro. Muitas de suas espécies, porém, se destacam nesse ecossistema por formarem grandes comunidades em associações diversas (Araújo \& Henriques 1984). Para estes autores, um bom exemplo são os "scrub" de Clusia, que formam a comunidade dos cordões arenosos pós-praia, de cobertura descontínua, caracterizados por moitas que atingem $4 \mathrm{~m}$ de altura, freqüentemente formados em torno de um indivíduo de Clusia onde se agregam ervas ou arbustos baixos, com predomínio de espécies de Bromeliaceae. Já a comunidade de Symphonia globulifera L.f. e Calophyllum brasiliense Cambess. dominam a

1. Universidade Federal do Rio de Janeiro, Museu Nacional, Departamento de Botânica, Quinta da Boa Vista, São Cristóvão, 20940-040 Rio de Janeiro, RJ, Brasil.

2. Autor para correspondência: vesteves@acd.ufrj.br comunidade "Floresta periodicamente inundada" caracterizada por depressões úmidas separando cordões arenosos paralelos, com árvores de $10 \mathrm{a}$ $15 \mathrm{~m}$ alt. (Araújo \& Henriques 1984).

Em continuidade ao estudo palinológico da vegetação existente nas restingas do Estado do Rio de Janeiro (Gonçalves-Esteves et al. 1992), neste trabalho foram analisados os grãos de pólen de oito espécies pertencentes à família Clusiaceae Lindl. São elas: Calophyllum brasiliense Cambess., Clusia criuva Cambess., C. hilariana Schltdl., C. lanceolata Cambess., C. parviflora (Sald.) Engl., Garcinia brasiliensis Mart., Kielmeyera membranacea Casar. e Symphonia globulifera L.f.

\section{Material e métodos}

O material estudado foi retirado de exsicatas depositadas nos herbários GUA (Herbário Alberto Castellanos, FEEMA, Rio de Janeiro) e R (Herbário do Departamento de Botânica, Museu Nacional - UFRJ). No material examinado, listado a seguir, o asterisco $(*)$ indica aquele que foi usado como padrão. Material utilizado foi: Calophyllum brasiliense: BRASIL: RIO DE JANEIRO: Carapebus, Fazenda Retiro, 3 km depois da Lagoa 
Comprida, 18/10/1995, I.M. da Silva 285 (*R); idem, Restinga de Carapebus, 05/6/1979, D. Araújo 3107 (GUA); Clusia criuva: BRASIL: Rio de JANeIRo: Carapebus, Praia de Carapebus, 4/11/1987, A. Souza 1903 (R); idem, idem, Poça das Lavagens, 14/9/1995, M.G. Santos 445 (R); Casimiro de Abreu, Barra de São João, 27/11/1953, F. Segadas-Vianna s.n. $(* \mathrm{R})$; Clusia hilariana: BRASIL: RIO DE JANEIRO: Carapebus a 2 km da Praia de Carapebus, 28/9/1994, J. Fontella 3123 (R); Casimiro de Abreu, 21/11/1986, A. Souza 1541 (R); Itaipuaçu, 12/12/1991, A. Souza $1455(* R)$. Clusia lanceolata: BRASIL: Rio DE JANEIRO: Itaipuaçu, 13/8/1984, J. Augusto \& J. Cardoso 331 (*R); Maricá, restinga aberta, 14/1/1999, M.C. Correia \& H.A. Lima S.N. (R); idem, 28/6/1983, D.S. Pedrosa 945 (GUA). Clusia parviflora: BRASIL: Rio DE JANEIRO: Angra dos Reis, Ilha Grande, 28/11/1989, D. Araújo 9019 (*GUA); idem, idem, 14/12/1983, D.S. Pedrosa 1039 (GUA). Garcinia brasiliensis: BRASIL: Rio DE JANEIRO: Itaipuaçu, 26/9/1988, M. Alves 165 \& H. Pereira $22(* \mathrm{R})$; Kielmeyera membranacea: BRASIL: RIO DE JANEIRO: Carapebus, Restinga de Carapebus, 12/12/1991, A. Souza S.N. (*R); idem, idem, 5/ 5/1997, M.C. Oliveira 478 (R). Symphonia globulifera: BRASIL: RIO DE JANEIRO: Carapebus, Restinga de Carapebus, 28/2/1996, A. Souza $3817(* R)$; idem, próximo à Lagoa de Cabiúnas, 21/5/1997, M.C. de Oliveira 593 (R).

Para o estudo em microscópio de luz (modelo Hund H500), o material polínico foi preparado segundo o método acetolítico de Erdtman (1952). As lâminas obtidas foram incorporadas à Palinoteca do Setor de Palinologia do Departamento de Botânica do Museu Nacional. Foram mensurados, aleatoriamente, 25 grãos de pólen de cada espécie. Calculou-se a média aritmética $(\overline{\mathrm{x}})$ baseada na medida do diâmetro polar (P) e do diâmetro equatorial (E), sempre que os grãos de pólen se apresentavam em vista equatorial e do diâmetro equatorial (DEVP) e do lado do apocolpo (LA) quando em vista polar. Com os resultados obtidos nas mensurações, estabeleceu-se o desvio-padrão da amostra (s), o desvio-padrão da média $\left(\mathrm{S}_{\bar{x}}\right)$, o coeficiente de variabilidade (cv\%), o intervalo de confiança a 95\% de significância (I.C. a 95\%) e a faixa de variação. Todas as medidas foram obtidas no prazo máximo de sete dias após a acetólise a fim de se evitar alterações nas dimensões dos grãos de pólen (SalgadoLabouriau 1973).

A denominação da área polar e do tamanho da abertura estão de acordo com a classificação estabelecida por Faegri \& Iversen (1966) para o índice da área polar.

Os valores apresentados para o diâmetro do poro, comprimento e largura do colpo, a espessura da exina, sexina e nexina, o diâmetro equatorial em vista polar e o lado do apocolpo, são resultados da média aritmética de 10 medidas.

Para análise em microscopia eletrônica de varredura (MEV) os grãos de pólen, não acetolisados, foram espalhados, diretamente, sobre suportes metálicos previamente recobertos por fita de carbono e, em seguida, o material recebeu uma fina camada de ouro paládio por cerca de três minutos sendo, posteriormente, analisado em aparelho Zeiss DSM 960.

A terminologia adotada foi a de Punt et al. (1999).
As fotomicrografias foram realizadas através de equipamento Hund H-500 com objetiva de $100 \mathrm{X}$ e as eletromicrografias, no Laboratório de Metalurgia da PUCRio, em aparelho Zeiss DSM960.

\section{Resultados}

Calophyllum brasiliense (figuras 1-8) - Grãos de pólen médios, oblato-esferoidais (tabela 1), isopolares, 3-colporados, âmbito subcircular, área polar pequena (IAP $=0,48$ ), exina granulada. Colpo longo, de extremidades agudas (figuras 3,4), endoabertura lalongada de extremidades obtusas (figura 6). Sexina menos espessa que a nexina. Em MEV (figuras 4,7) pode-se comprovar que a exina é rugulada porém, as rúgulas são, em algumas regiões, arredondadas, curtas, principalmente no mesocolpo, assemelhando-se a grânulos (figura 8). O material de comparação (tabela 2) apresentou as mesmas características morfopolínicas do material padrão e os valores dos diâmetros polar e equatorial não ficaram dentro dos limites do I.C. a $95 \%$ porém, mantiveram-se dentro dos limites da faixa de variação.

Medidas $(\mu \mathrm{m})$ : colpo (compr. ca. 27,5 e larg. ca. 8,0); endoabertura (compr. ca. 9,7 e larg. ca. 17,0); diâmetro equatorial em vista polar ca. 38,5; lado do apocolpo ca. 13,4; exina ca. 2,2; sexina ca. 1,0; nexina ca. 1,2 .

Clusia L. (figuras 9-35) - Grãos de pólen pequenos ou médios, suboblatos ou oblatoesferoidais, isopolares, 3-porados ou 3-colporados, área polar grande, exina rugulada ou reticulada.

C. criuva (figuras 9-16) - Grãos de pólen pequenos, oblato-esferoidais (tabela 1), isopolares, 3-porados, com opérculo ornamentado, âmbito subcircular, área polar grande (IAP $=0,62)$, exina reticulada, formada por muros largos, simplescolumelados e de lumens heterogêneos (figuras 10,11). As aberturas são recobertas por opérculo granulado, o que dificulta a observação do poro (figuras 14,15). Sexina ligeiramente menos espessa que a nexina. Em MEV, pode-se observar que os muros do retículo são rasos, largos, de superfície irregular pela presença de pequenos grânulos (figura 16). Os materiais de comparação (tabela 2) apresentaram características semelhantes às do material padrão e os valores dos diâmetros polar e equatorial não ficaram dentro dos limites do I.C. a 95\% porém, mantiveram-se dentro dos limites da faixa de variação. 

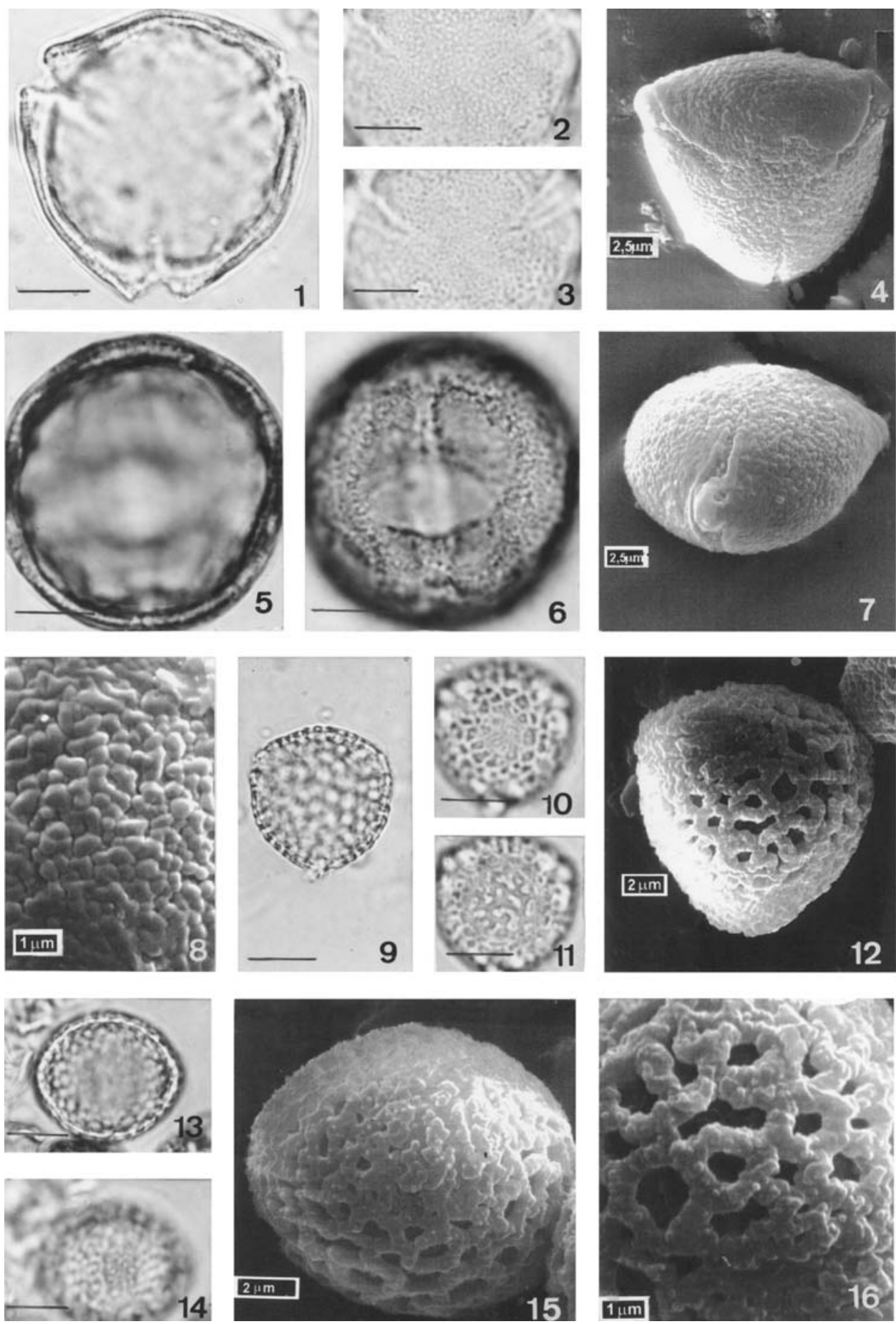

Figuras 1-16. Fotomicrografias e eletromicrografias dos grãos de pólen de espécies de Clusiaceae. 1-8. Calophyllym brasiliense. 1. Corte óptico em vista polar. 2-3. L.O. 4. Vista polar (MEV). 5. Corte óptico em vista equatorial. 6. Abertura em vista equatorial. 7. Abertura em vista equatorial (MEV). 8. Detalhe da superfície (MEV). 9-16. Clusia criuva. 9. Corte óptico em vista polar. 10-11. L.O. 12. Vista polar (MEV). 13. Contorno em vista equatorial. 14. Abertura em vista equatorial. 15. Abertura em vista equatorial (MEV). 16. Detalhe da superfície (MEV). Escala $=10 \mu \mathrm{m}$. 
Tabela 1. Medidas $(e m \mu \mathrm{m})$ dos grãos de pólen em vista equatorial $(\mathrm{n}=25) . \overline{\mathrm{x}}=$ média aritmbética; $\mathrm{s}_{\overline{\mathrm{x}}}=$ desvio padrão da média; $\mathrm{s}=$ desvio padrão da mostra; $\mathrm{cv}=$ coeficiente de variabilidade; $\mathrm{IC}=$ intervalo de confiança; $\mathrm{P} / \mathrm{E}=$ relação entre a média do diâmetro polar e do diâmetro equatorial.

\begin{tabular}{|c|c|c|c|c|c|c|c|c|c|c|c|}
\hline \multirow[b]{2}{*}{ Espécies } & \multicolumn{5}{|c|}{ Diâmetro polar } & \multicolumn{5}{|c|}{ Diâmetro equatorial } & \multirow[b]{2}{*}{$\mathrm{P} / \mathrm{E}$} \\
\hline & $\begin{array}{l}\text { Faixa de } \\
\text { variação }\end{array}$ & $\bar{x}+S_{\bar{x}}$ & $\mathrm{~s}$ & $\mathrm{cv} \%$ & IC a $95 \%$ & $\begin{array}{l}\text { Faixa de } \\
\text { variação }\end{array}$ & $\overline{\mathrm{x}}+\mathrm{s}_{\mathrm{x}}$ & $\mathrm{s}$ & $\mathrm{cv} \%$ & IC a $95 \%$ & \\
\hline Calophyllum brasiliense & $32,5-37,7$ & $35,3+0,2$ & 1,4 & 3,9 & $34,9-35,7$ & $37,5-40,0$ & $38,9+0,2$ & 1,2 & 3,1 & $38,5-39,3$ & 0,91 \\
\hline Clusia criuva & $18,1-21,2$ & $19,3+0,2$ & 0,9 & 4,6 & $18,9-19,7$ & $20,0-22,5$ & $21,7+0,2$ & 1,0 & 4,7 & $21,3-22,1$ & 0,89 \\
\hline C. hilariana & $19,3-20,0$ & $20,3+0,1$ & 0,7 & 3,5 & $20,1-20,5$ & $20,0-21,8$ & $20,5+0,1$ & 0,5 & 2,6 & $20,3-20,7$ & 0,99 \\
\hline C. lanceolata & $25,0-28,7$ & $26,2+0,2$ & 1,2 & 4,5 & $25,8-26,6$ & $28,7-35,0$ & $32,4+0,3$ & 1,5 & 4,8 & $31,8-33,0$ & 0,81 \\
\hline C. parviflora & $17,5-20,0$ & $18,1+0,1$ & 0,9 & 4,9 & $17,9-18,3$ & $20,0-22,5$ & $20,8+0,1$ & 0,9 & 4,3 & $20,6-21,0$ & 0,87 \\
\hline Garcinia brasiliensis & $36,2-38,7$ & $37,5+0,2$ & 1,1 & 3,1 & $37,1-37,9$ & $35,0-37,5$ & $35,0+0,2$ & 1,0 & 2,9 & $34,6-35,4$ & 1,07 \\
\hline Kielmeyera membranacea & $48,7-56,2$ & $53,3+0,4$ & 2,1 & 3,9 & $52,5-54,1$ & $41,2-45,0$ & $42,5+0,2$ & 1,4 & 3,2 & $42,1-42,9$ & 1,25 \\
\hline Symphonia globulifera & $50,0-58,7$ & $53,6+0,5$ & 2,6 & 5,8 & $52,6-54,6$ & $60,0-67,5$ & $64,1+0,4$ & 2,3 & 3,7 & $63,3-64,9$ & 0,83 \\
\hline
\end{tabular}

Medidas $(\mu \mathrm{m})$ : poro (compr. 6,5 e larg. 6,1); diâmetro equatorial em vista polar ca. 21,1; lado do apoporo ca. 13,2; exina ca. 1,9; sexina ca. 0,9 ; nexina ca. 1,0 .

C. hilariana (figuras 17-22) - Grãos de pólen pequenos, oblato-esferoidais (tabela 1), isopolares, 3-porados, com opérculo ornamentado, âmbito circular, área polar grande (IAP $=0,50$ ), exina reticulada, formada por muros largos, simplescolumelados e de lúmens heterogêneos (figuras 18-20). Em MEV, observa-se que o retículo, em algumas regiões, tem o aspecto de rúgula devido à redução do espaço entre os lumens. $\mathrm{O}$ muro do retículo apresenta superfície lisa (figura 22). Sexina ligeiramente mais espessa que a nexina. Os materiais de comparação (tabela 2) apresentaram características semelhantes às do material padrão e os valores dos diâmetros polar e equatorial não ficaram dentro dos limites do I.C. a $95 \%$ porém, mantiveram-se dentro dos limites da faixa de variação.

Medidas $(\mu \mathrm{m})$ : poro (compr. ca. 16,0 e larg. ca. 11,3); diâmetro equatorial em vista polar ca. 27,0; lado do apoporo ca. 13,5; exina ca. 1,9; sexina ca. 1,0 ; nexina ca. 0,9 .

Clusia lanceolata (figuras 23-27) - Grãos de pólen médios, suboblatos (tabela 1), isopolares, 3colporados, âmbito circular, área polar grande (IAP $=0,51)$, exina rugulada. Cólporo com membrana ornamentada, colpos curtos. Em MEV pode-se notar que o colpo é ornado por uma margem espessa e a endoabertura é visível (figuras 26, 27). Sexina menos espessa que a nexina. Os materiais de comparação (tabela 2) apresentaram características semelhantes às do material padrão e os valores dos diâmetros polar e equatorial ficaram, na sua maioria, dentro dos limites do I.C. a $95 \%$ e da faixa de variação.

Medidas $(\mu \mathrm{m})$ : colpo (compr. ca. 10,8 e larg. ca. 2,3); diâmetro equatorial em vista polar ca. 36,0; lado do apocolpo ca. 18,5; exina ca. 2,3; sexina ca. 1,0; nexina 1,3 .

Clusia parviflora (figuras 28-35) - Grãos de pólen pequenos, suboblatos (tabela 1), isopolares, 3-porados, âmbito circular, área polar grande (IAP $=0,64$ ), exina reticulada (figuras 29,30 ). Abertura com opérculo não ornamentado (figuras 33, 34). Em MEV verifica-se que o retículo possui muros largos, grossos, com superfície lisa (figura 35). Sexina menos espessa que a nexina. O material de comparação (tabela 2) apresentou características semelhantes às do material padrão e os valores dos diâmetros polar e equatorial não ficaram dentro dos limites do IC a $95 \%$ porém, mantiveram-se dentro dos limites da faixa de variação.

Medidas $(\mu \mathrm{m})$ : diâmetro do poro (ca. 6,0); diâmetro equatorial em vista polar ca. 19,8; lado do apoporo ca. 12,6; exina ca. 2,0; sexina ca. 0,9; nexina 1,1 .

Garcinia brasiliensis (figuras 36-42) - Grãos de pólen médios, prolato-esferoidais (tabela 1), isopolares, 3-colporados, âmbito subtriangular, área polar muito pequena (IAP $=0,18$ ), exina rugulada (figuras 37,38 ). Cólporos com membrana ornamentada, colpos muito longos com constricção na região mediana, endoabertura lalongada recoberta 

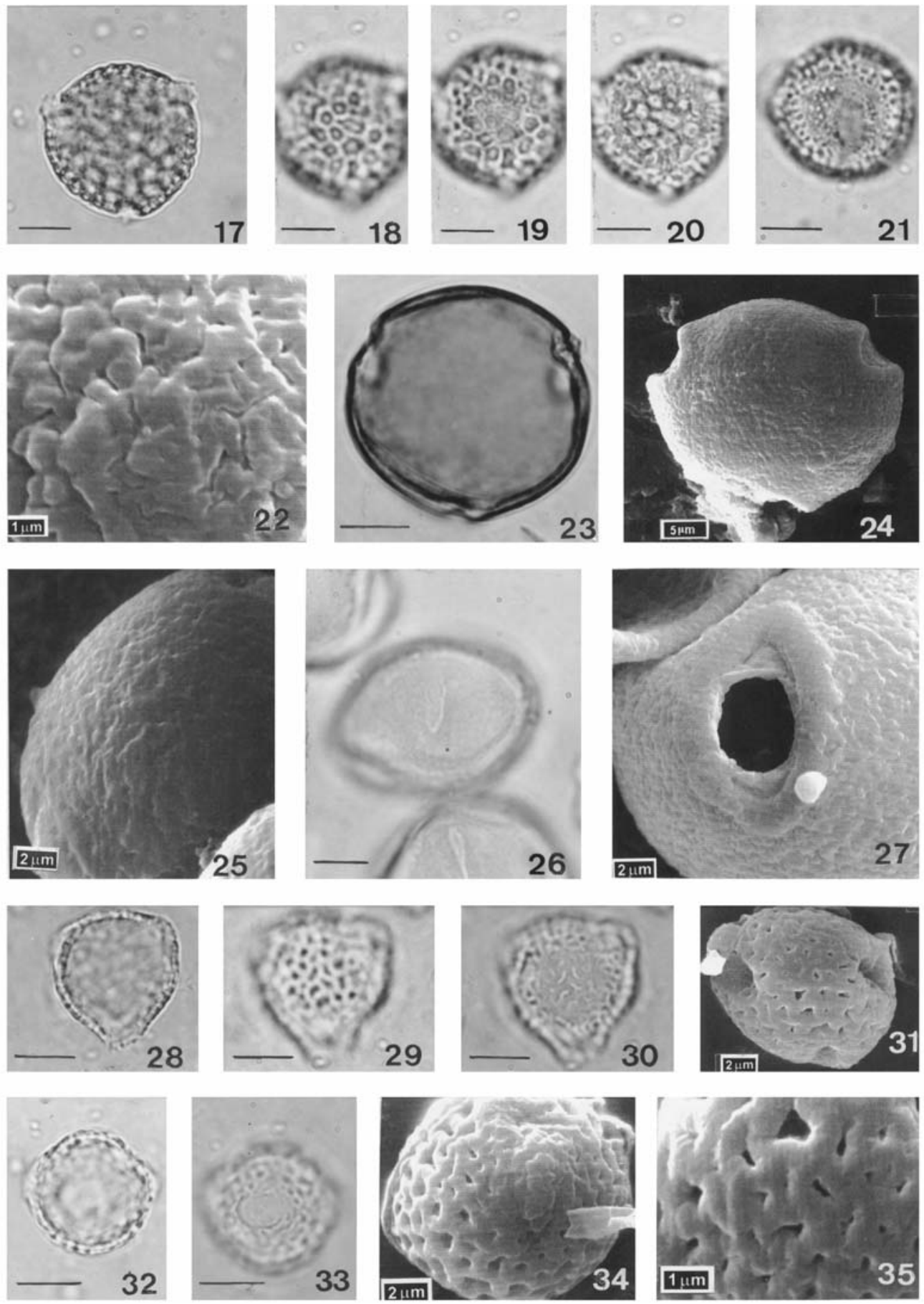

Figuras 17-35. Fotomicrografias e eletromicrografias dos grãos de pólen de espécies de Clusiaceae. 17-22. Clusia hilariana. 17. corte óptico em vista polar. 18-20. L.O. 21. Abertura em vista equatorial. 22. Detalhe da superfície (MEV). 23-27. Clusia lanceolata. 23. Contorno em vista polar. 24. Vista polar (MEV). 25. Detalhe da superfície em vista polar (MEV). 26. Abertura em vista equatorial. 27. Abertura em vista equatorial (MEV). 28-35. Clusia parviflora. 28. Corte óptico em vista polar. 29-30. L.O. 31. Vista polar (MEV). 32. Corte óptico em vista equatorial. 33. Abertura em vista equatorial. 34. Abertura em vista equatorial $(\mathrm{MEV}) .35$. Detalhe da superfície. Escala $=10 \mu \mathrm{m}$. 
532 V. Gonçalves-Esteves et al:: Palinologia de espécies de Clusiaceae das restingas do Rio de Janeiro

Tabela 2. Medidas (em $\mu \mathrm{m})$ dos grãos de pólen, do material de comparação, em vista equatorial $(\mathrm{n}=25) . \overline{\mathrm{x}}=$ média aritmética; $\mathrm{P} / \mathrm{E}=$ relação entre a média do diâmetro polar e do diâmetro equatorial.

\begin{tabular}{|c|c|c|c|}
\hline Espécies & $\begin{array}{l}\text { Diâmetro } \\
\text { polar } \\
\overline{\mathrm{x}}\end{array}$ & $\begin{array}{c}\text { Diâmetro } \\
\text { equatorial } \\
\overline{\mathrm{x}}\end{array}$ & $\mathrm{P} / \mathrm{E}$ \\
\hline $\begin{array}{l}\text { Calophyllum brasiliense } \\
\text { (D. Araújo 3107) }\end{array}$ & 34,8 & 38,2 & 0,91 \\
\hline $\begin{array}{l}\text { Clusia criuva } \\
\quad \text { (A.Souza 1903) } \\
\text { (M.G. Santos 445) }\end{array}$ & $\begin{array}{l}18,5 \\
20,0\end{array}$ & $\begin{array}{l}20,0 \\
21,9\end{array}$ & $\begin{array}{l}0,92 \\
0,91\end{array}$ \\
\hline $\begin{array}{l}\text { C. hilariana } \\
\text { (A. Souza 1541) } \\
\text { (J. Fontella 3123) }\end{array}$ & $\begin{array}{l}20,0 \\
19,5\end{array}$ & $\begin{array}{l}21,2 \\
21,1\end{array}$ & $\begin{array}{l}0,94 \\
0,92\end{array}$ \\
\hline $\begin{array}{l}\text { C. lanceolata } \\
\text { (D.S. Pedrosa 945) } \\
\text { (M.C. Correia \& H.A. Lima) }\end{array}$ & $\begin{array}{l}25,0 \\
25,4\end{array}$ & $\begin{array}{l}32,5 \\
33,0\end{array}$ & $\begin{array}{l}0,76 \\
0,76\end{array}$ \\
\hline $\begin{array}{l}\text { C. parviflora } \\
\text { (D.S. Pedrosa 1039) }\end{array}$ & 17,6 & 19,0 & 0,92 \\
\hline $\begin{array}{l}\text { Garcinia brasiliensis } \\
\quad \text { (A. Costa } 654)\end{array}$ & 36,5 & 35,5 & 1,04 \\
\hline $\begin{array}{l}\text { Kielmeyera membranacea } \\
\text { (M.C. Oliveira 478) }\end{array}$ & 49,3 & 37,5 & 1,31 \\
\hline $\begin{array}{r}\text { Symphonia globulifera } \\
\text { (M.C. Oliveira 593) }\end{array}$ & 51,5 & 62,2 & 0,82 \\
\hline
\end{tabular}

por membrana ornamentada (figura 41). Em MEV pode-se confirmar a presença de membrana ornamentada no colpo e a ornamentação da exina mais conspícua no mesocolpo e inconspícua na região do apocolpo (figuras 39,42 ). Sexina menos espessa que a nexina. O material de comparação (tabela 2) apresentou características semelhantes às do material padrão e os valores dos diâmetros polar e equatorial não ficaram dentro dos limites do I.C. a 95\% porém, mantiveram-se dentro dos limites da faixa de variação.

Medidas ( $\mu \mathrm{m})$ : colpo (compr. ca. 30,5 e larg. ca. 4,0); endoabertura (compr. ca. 5,1 e larg. 7,4); diâmetro equatorial em vista polar ca. 37,5; lado do apocolpo ca. 6,6; exina ca. 3,0; sexina ca. 1,0; nexina 1,9 .

Kielmeyera membranacea (figuras 43-51) Grãos de pólen grandes, subprolatos (tabela 1), isopolares, 3-colporados, âmbito subcircular, área polar muito pequena (IAP $=0,21$ ), exina rugulada, com perfurações (figuras 44-47). Colpos muito longos, com margem, endoabertura pronunciadamente lalongada, com extremidades agudas, recoberta por membrana ornamentada. O colpo apresenta constricção na região mediana. Em MEV, observase que o colpo é largo, pouco profundo; na região da endoabertura a exina torna-se mais espessa formando margem proeminente (figura 51), a superfície da exina apresenta rúgulas mais conspícuas no mesocolpo e menos conspícuas, com perfurações no apocolpo (figura 48). Sexina ligeiramente mais espessa que a nexina. O material de comparação (tabela 2) apresentou características semelhantes às do material padrão e os valores dos diâmetros polar e equatorial não ficaram dentro dos limites do I.C. a 95\% porém, mantiveram-se dentro dos limites da faixa de variação.

Medidas ( $\mu \mathrm{m})$ : colpo (compr. ca. 42,0 e larg. ca. 17,1), endoabertura (compr. ca. 7,0 e larg. 7,1); diâmetro equatorial em vista polar ca. 45,2; lado do apocolpo ca. 9,6; exina ca. 2,5; sexina ca. 1,3; nexina 1,2 .

Symphonia globulifera (figuras 52-63) - Grãos de pólen grandes, suboblatos (tabela 1), isopolares, 4-6-porados (figuras 52-54), âmbito, predominantemente, pentagonal, área polar pequena $(\mathrm{IAP}=0,45)$, exina rugulada, formada por uma camada fina de columelas (figuras 55-57). O teto é muito fino na região do mesoporo tornando-se mais espesso próximo à abertura (figuras 55, 59). A sexina é menos espessa que a nexina; nexinas 1 e 2 são bem visíveis sendo a nexina 1 muito mais espessa. O poro 

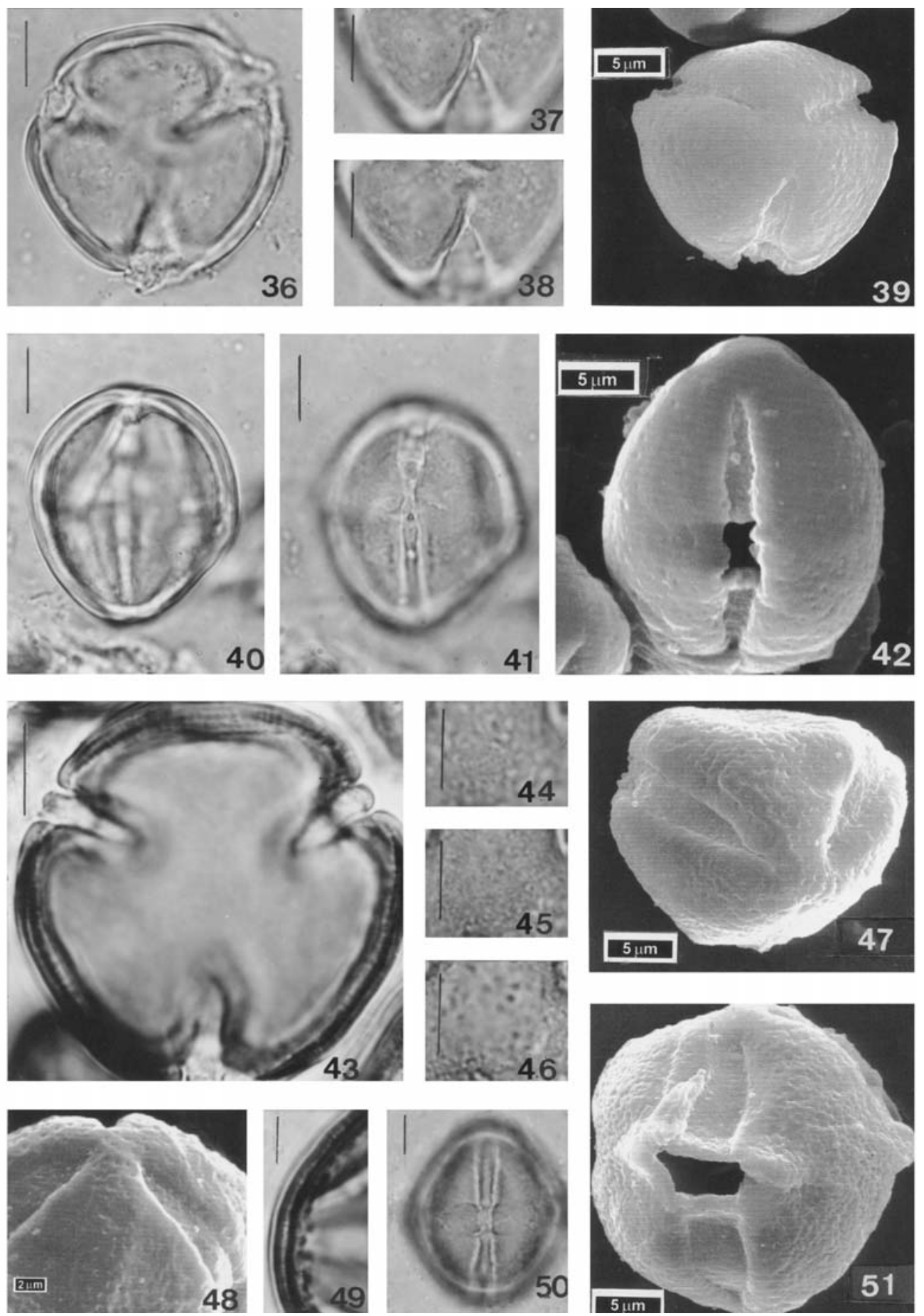

Figuras 36-51. Fotomicrografias e eletromicrografias dos grãos de pólen de espécies de Clusiaceae. 36-42. Garcinia brasiliensis. 36. Corte óptico em vista polar. 37-38. L.O. 39. Vista polar (MEV). 40. Contorno em vista equatorial. 41. Abertura em vista equatorial. 42. Abertura em vista equatorial (MEV). 43-51. Kielmeyera membranacea. 43. Corte óptico em vista polar. 4446. L.O. 47. Vista polar (MEV). 48. Detalhe da superfície no apocolpo em vista polar (MEV). 49. Detalhe do corte óptico em vista equatorial 50. Abertura em vista equatorial. 51. Abertura e superfície em vista equatorial (MEV). Escala $=10 \mu \mathrm{m}$. 
534 V. Gonçalves-Esteves et al:: Palinologia de espécies de Clusiaceae das restingas do Rio de Janeiro
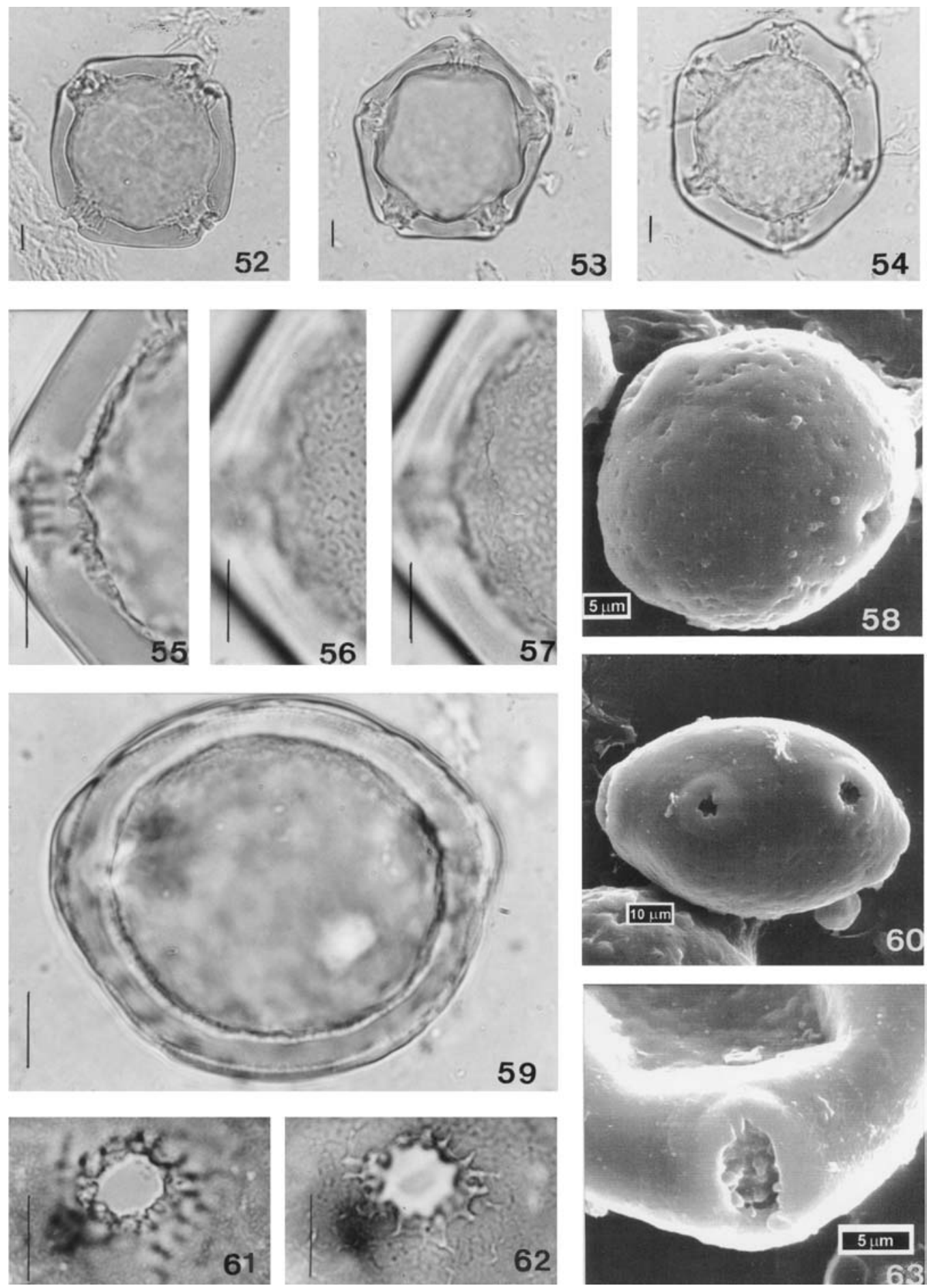

Figuras 52-63. Fotomicrografias e eletromicrografias dos grãos de pólen de espécies de Clusiaceae. 52-63. Symphonia globulifera. 52-54. Corte óptico e variação no número de aberturas em vista polar. 55. Detalhe do corte óptico em vista polar. 56-57. L.O. 58. Vista polar (MEV). 59. Corte óptico em vista equatorial. 60. Vista equatorial e aberturas (MEV). 61-62. Detalhe da abertura e superfície em vista equatorial. 63. Detalhe da abertura e superfície em vista equatorial (MEV). Escala $=10 \mu \mathrm{m}$. 
apresenta margem espessa formada por columelas bem visíveis quando observadas em corte óptico (figura 55). Em MEV observa-se que os poros possuem opérculo granulado abaixo da margem (figura 63); a exina é levemente rugulada nos pólos, com perfurações esparsas e quase psilada no mesoporo. Em relação à variabilidade no número de aberturas a porcentagem obtida foi: 4-porados $42 \%, 5$-porados - $55 \%$ e 6 -porados - $3 \%$. O material de comparação (tabela 2) apresentou características semelhantes às do material padrão e os valores dos diâmetros polar e equatorial não ficaram dentro dos limites do I.C. a $95 \%$ porém, dentro dos limites da faixa de variação.

Medidas $(\mu \mathrm{m})$ : diâmetro do poro ca. 7,4; grãos de pólen 4-porados: diâmetro equatorial em vista polar: ca. 60,0; lado do apoporo ca. 31,6; grãos de pólen 5-porados: diâmetro equatorial em vista polar ca. 62,4 ; lado do apoporo ca. 27,9 ; exina ca. 9,1 ; sexina ca. 1,6; nexina 1 ca. 6,4 ; nexina 2 ca. 1,2 .

\section{Chave para identificação das espécies de Clusiaceae estudadas}

1. Grãos de pólen porados

2. Grãos de pólen grandes, 4-6-porados, exina rugulada. Symphonia globulifera

2. Grãos de pólen pequenos, 3-porados, exina reticulada

3. Grãos de pólen suboblatos, poros com opérculo não ornamentado Clusia parviflora

3. Grãos de pólen oblato-esferoidais, poros com opérculo ornamentado 4. Muros do retículo com superfície ornamentada. Clusia criuva 4. Muros do retículo com superfície lisa. Clusia hilariana

1. Grãos de pólen colporados

5. Cólporos com constricção mediana

6. Grãos de pólen médios, prolato-esferoidais Garcinia brasiliensis

6. Grãos de pólen grandes, subprolatos. Kielmeyera membranacea

5. Cólporos sem constricção mediana

7. Grãos de pólen oblato-esferoidais, com área polar pequena, colpos longos, exina granulada. Calophyllum brasiliense

7. Grãos de pólen suboblatos, área polar grande, colpos curtos, exina rugulada......Clusia lanceolata

\section{Discussão}

As espécies de Clusiaceae aqui analisadas apresentaram diferenças morfológicas nos seus grãos de pólen. Os cinco gêneros estudados puderam ser separados, principalmente, pelo tipo e número de aberturas (porados ou colporados), poros com ou sem opérculo, colpos com ou sem constricção mediana, ornamentação da exina, tamanho e forma dos grãos de pólen. A maioria das espécies de Clusia apresentou poros e exina reticulada, exceto $C$. lanceolata que se caracterizou por possuir cólporos e exina rugulada. Na chave elaborada, as espécies puderam ser separadas pelas características morfopolínicas. Symphonia globulifera foi a única espécie com variabilidade no número de aberturas (4-6 poros) e nexina muito mais espessa que a sexina.
No levantamento bibliográfico realizado foram poucos os trabalhos encontrados sobre a palinologia de Clusiaceae. Pode-se citar Erdtman (1952), que estudou 35 espécies pertencentes a 20 gêneros, dentre eles, Calophyllum L., Garcinia L., Kielmeyera Mart. e Symphonia L. De forma geral, os resultados aqui obtidos se assemelham aos de Erdtman (1952) quando se refere às características dos gêneros. No entanto, a espécie de Kielmeyera, observada por Ertdman (1952), apresentou grãos de pólen em tétrade, enquanto que a espécie aqui estudada possui grãos de pólen em mônades. Barth (1963) analisou os grãos de pólen de Kielmeyera angustifolia, descrevendoos como reunidos em tétrade. Barth (1980) associando o estudo polínico com o de um taxonomista, fez um trabalho muito detalhado sobre Kielmeyera criando cinco tipos e 14 
subtipos. Barth (1980) concluiu que as espécies desse gênero podem apresentar grãos de pólen em mônades, tétrades ou políades e, dentre as espécies enfocadas, $K$. excelsa var. membranacea (atualmente K. membranacea) foi objeto desse estudo que, para a autora, apresentou grãos de pólen em mônades, teto psilado ou perfurado. Para as autoras do presente trabalho esta espécie possui exina rugulada com perfurações esparsas.

Vasconcelos et al. (1972) dividiu Clusiaceae em quatro grupos de acordo com a unidade polínica e o tipo de abertura. Os gêneros aqui analisados puderam ser enquadrados nos grupos criados por Vasconcelos et al. (1972) com exceção de Kielmeyera que, para a autora, constituiu o grupo de grãos de pólen em tétrade. Barth (1963), estudou os grãos de pólen de Calophyllum brasiliense, Clusia criuva e Rheedia gardneriana Planch. \& Triana (atualmente Garcinia). Os resultados aqui apresentados foram semelhantes àqueles encontrados por Barth (1963), exceto pela ornamentação da exina que, para a autora, era reticulada em $C$. brasiliense e pouco nitidamente reticulada para a espécie de Garcinia. Seetharam \& Maheshwari (1986) estudaram em MEV, 10 espécies de Clusiaceae pertencentes a oito gêneros e, dentre eles, Garcinia. As espécies examinadas pelos autores apresentaram grãos de pólen espiculados, características muito diferentes daquelas aqui encontradas. Mais tarde, Seetharam (1989) fez um estudo mais amplo sobre este gênero avaliando, também, a diversidade do androceu, a evolução e a distribuição geográfica de suas espécies. Criou oito tipos polínicos com base nas características da abertura. Apesar da espécie aqui estudada não ter sido analisada pelo autor supracitado, pelas características dos tipos polínicos, G. brasiliensis poderia ser enquadrada no tipo Longicolporado de Seetharam (1989).

Roubik \& Moreno (1991) estudaram 10 gêneros de Clusiaceae e, dentre eles, Calophyllum, Clusia, e Symphonia globulifera. As características das espécies no presente trabalho diferiram dos resultados dos autores acima citados, principalmente, no que se refere à ornamentação da exina. Com relação a Symphonia globulifera, Erdtman (1952) considerou o grão de pólen 4-porado o mais comum, encontrando-se também, segundo o autor, em menor quantidade, 3-porados. Esta espécie foi, também, aqui analisada e a diferença encontrada foi apenas com vistas ao número de aberturas. No presente trabalho, o mais comum foi 4-5-porados tendo sido também, encontrado grãos de pólen 6-porados.

Com base no estudo presente pode-se concluir que os grãos de pólen das espécies aqui estudadas são muito distintos, tratando-se, portanto, de um grupo euripolínico.

Agradecimentos - Ao Laboratório de Microscopia Eletrônica da PUC-Rio, na pessoa da MSc. Maria de Fátima S. Lopes, a quem devemos as ilustrações em MEV. Ao CNPq à FAPERJ e à FUJB pelos auxílios concedidos ao Laboratório de Palinologia.

\section{Referências bibliográficas}

ARAÚJO, D.S.D. \& HENRIQUES, R.P.B. 1984. Análise florística das restingas do Estado do Rio de Janeiro. In Restingas - origem, estrutura, processos (L.D. Lacerda, D.S.D. Araujo, R. Cerqueira \& B. Turcq, orgs.). Anais do Simpósio sobre restingas brasileiras, Universidade Federal Fluminense, Niterói, p.159-193.

BARTH, O.M. 1963. Catálogo sistemático dos pólens das plantas arbóreas do Brasil meridional. III Theaceae, Marcgraviaceae, Ochnaceae, Guttiferae e Quinaceae. Memórias do Instituto Oswaldo Cruz 61:89-110.

BARTH, O.M. 1980. Morfologia do pólen e palinotaxonomia do gênero Kielmeyera (Guttiferae). Rodriguésia 55:105-134.

ERDTMAN, G. 1952. Pollen morphology and plant taxonomy angiosperms. Almqvist \& Wilsell, Stockholm.

FAEGRI, K. \& INVERSEN, J. 1966. Textbook of modern pollen analysis. 2ed. Scandinavian University Books, Copenhagen.

GONÇALVES-ESTEVES, V.; MARTINS, V.L.C.; ESTEVES, R. \& SILVA, S.L.M. 1992. Estudo polínico em plantas de restinga do Estado do Rio de Janeiro Acanthaceae Juss. e Amaranthaceae Juss. Boletim do Museu Nacional (Nova Série, Botânica) 89:1-21.

PUNT, W., BLACKMORE, S., NILSSON, S. \& LE THOMAS, A. 1999. Glossary of pollen and spore terminology. [http:www.biol.ruu.nl/ palaeo/glossary/glos-int.htm]

ROUBIK, D.W. \& MORENO, J.E. 1991. Pollen and spores of Barro Colorado Island. Missouri Botanical Garden, Saint Louis.

SALGADO-LABOURIAU, M.L. 1973. Contribuição à palinologia dos cerrados. Academia Brasileira de Ciências, Rio de Janeiro.

SEETHARAM, Y.N. 1989. Diversity of androecium an pollen grains in the genus Garcinia L. and its bearing on geographical distribuition and evolution. Proceedings of the Indian Academy of Science 99:107-115.

SEETHARAM, Y.N. \& MAHESHWARI, J.K. 1986. Scanning electron microscopic studies on the pollen of some Clusiaceae. Proceedings of the Indian Academy of Science 96:217-226.

VASCONCELLOS, N.C., CARVALHO, M.J.C., ANDRADE, T.A.P. \& BERG, M.E.V.D. 1972. O pólen em plantas da Amazônia. Boletim do Museu Paraense Emílio Goeldi (Nova Série, Botânica) 44:1-12. 